\title{
Conditioned aversion is promoted by memory of CS-
}

\author{
DAVID KUCHARSKI, NORMAN G. RICHTER, and NORMAN E. SPEAR \\ State University of New York, Binghamton, New York
}

\begin{abstract}
Five experiments tested the effects of experience with a white compartment not paired with footshock (CS-) on conditioning of an aversion to a black compartment paired with footshock. As previously found with odors as CSs, a single pairing of the CS + with footshock yielded significant conditioning only if the animal was also exposed to CS-, with greater conditioning when the CS- exposure preceded the CS+ than when the CS+ preceded the CS-. If, however, the CSpreceded CS+ by a 24 -h interval, it was ineffective and no CS+ conditioning occurred. For adult rats, the effectiveness of the CS-/CS+ "integration" progressively decreased with increasing length of the interval separating their occurrence, although it was still significant (i.e., some $\mathrm{CS}+$ conditioning occurred) with a 12 -h CS- to CS+ delay. For preweanlings (16 days postnatal), no conditioning to CS+ occurred if the interval between $\mathrm{CS}-$ and $\mathrm{CS}+$ was $1 \mathrm{~h}$ or longer, although significant conditioning to CS+ did occur with a CS- to CS+ interval as long as $40 \mathrm{~min}$. It was as if active memory for the CS- at the time of CS+ exposure was necessary for CS+ condition. ing, and forgetting of the CS- memory proceeded more rapidly for preweanling than for adult rats. Collectively, these experiments extend results previously indicating that (1) the CS+ contiguous to the US may or may not be "selected" for conditioning, depending on the rat's exposure to, or memory for, a CS-, and (2) this stimulus selection might differ for immature and mature rats.
\end{abstract}

A variety of experiential manipulations have identified circumstances that determine which of several contiguous stimuli are "selected" for association in a learning task (e.g., latent inhibition, blocking, overshadowing; Mackintosh, 1974). Other findings indicate that there are certain ontogenetic and biological constraints that determine which stimuli within an episode are and which are not association. Haroutunian and Campbell (1979) found that animals younger than 10 days postnatal could associate an odor CS + with illness (induced by an injection of lithium chloride) but not with footshock. The young animals were at least as sensitive to the footshock employed as the older animals that readily formed the association. Garcia and Koelling (1966) reported that adult rats could easily form an association between taste and illness, but not between taste and shock. Other studies have demonstrated that both biological and experiential factors can interact to determine similar stimulus selection (Kelley, 1982). Recently, we have studied another experiential manipulation that determines when a contiguous conditioned stimulus (CS) will be selected for association with the unconditioned stimulus (US). Animals given an odor CS- (cue explicitly unpaired with footshock) were found to express greater aversions to the odor

This research was supported by a grant from the National Institute of Mental Health (1 R01 MH35219) to Norman E. Spear and NIMH Predoctoral Research Fellowship Award (1 F31 MH09058-01A1) to David Kucharski. The authors are grateful to Teri Tanenhaus for preparing this report. Requests for reprints should be addressed to Norman E. Spear, Department of Psychology, State University of New York at Binghamton, Binghamton, NY 13901.
$\mathrm{CS}+$ (cue followed by footshock) than animals given only the CS+ (Bryan, 1979; Kucharski \& Spear, 1984). Some background to this work is in order.

Doctoral dissertation research conducted in our laboratory had indicated that rats as young as 7 days postnatal were quite capable of acquiring odor-footshock associations (Bryan, 1979). Such conditioning at this young age was not observed by Haroutunian and Campbell (1979) in the study mentioned earlier, but the procedures were different. Kucharski and Spear (1984) tested the notion that part of the critical procedural difference in the latter study was the inclusion of a CS- during the conditioning phase, which might be more important earlier in development. Kucharski and Spear found that 8-day-old animals needed several conditioning trials and a CS- in order to express aversions to the $\mathrm{CS}+$, whereas both 15 and 50-day-old animals given the same number of conditioning trials expressed aversions to the CS+ without exposure to a CS- . Nonetheless, these aversions were enhanced if animals of any age were exposed to the CS- . For the 15- and 50-day-old animals, substantial aversions to the CS+ were formed after just one conditioning trial, if they were exposed to the CS-

One hypothesis is that the CS- allows the animal to focus on the relevant cue, as defined by the experimenter. In other words, in addition to the CS+ odor cue, the animal may be attending to a multitude of stimuli that are also predictive of footshock, for example, the conditioning apparatus, the grid floor beneath the apparatus that delivers the footshock, the handling of the animal by the experimenter, and so forth. By maintaining these stimuli as redundant contextual components of the conditioning 
situation during exposure to the $\mathrm{CS}-$, the animal learns that the best predictor of footshock is the odor CS+.

A similar interpretation has been proposed for instrumental discrimination learning (Mackintosh, 1974, 1975; Sutherland \& Mackintosh, 1971). Differential reinforcement for responding to $\mathrm{S}+$ and $\mathrm{S}-$ is believed to increase attention to relevant stimuli. For example, many experiments have shown that rats have a marked position preference in the early stages of an appetitive-visual discrimination problem. Presumably, as the animal makes correct and incorrect choices, it can learn the correlation between $\mathrm{S}_{+}, \mathrm{S}-$, and reinforcement. Therefore, the preference for position is supplanted by a preference for $\mathrm{S}+$ as training continues. Our suggestion is that animals need not make specific instrumental responses for a similar process to occur with a classical conditioning paradigm employing both a CS+ and CS-.

The present series of experiments tested the generality of this phenomenon to a classical conditioning paradigm employing visual CSs. The effects of Kucharski and Spear (1984) could be unique to odors, which share a variety of properties that are difficult to control experimentally. In the first experiment, all animals were confined to a black compartment where footshock was administered (the CS+ compartment). Then some of the animals were confined also to the white compartment, where footshock was not administered (the CS- compartment). The animals were later tested for the amount of time spent in the black side of the black/white test apparatus when they were free to locomote between the compartments. Experiment 2 was designed to determine whether the CS- promoted learning of an aversion to the black side of the compartment or a preference for the white side of the compartment. Experiment 3 tested the effects of delay between exposures to the white and black chambers for adult animals. Experiments $4 \mathrm{~A}$ and $4 \mathrm{~B}$ were designed to examine the generality of these effects to preweanling rats.

\section{EXPERIMENT 1}

Kucharski and Spear (1984) reported that adult animals given exposures to one odor-footshock pairing did not express an aversion to this odor unless the animal had also been exposed to a CS-. Also, animals of all ages tended to express stronger aversions if they had been given CSexposure, especially if the CS- had preceded the CS+ exposure rather than vice versa. It is possible that these effects are limited to olfaction, a chemically mediated sensory system that can have longer functional durations than do such senses as vision, which operates on more distal stimuli. The purpose of the present experiment was to determine whether similar effects occur when a largely visual CS+ is paired with footshock. "Experimental" animals were separately confined for 20 sec in a black chamber, where footshock was administered during Seconds 8-10 and 18-20. The animals were, in addition, confined in the white chamber for $20 \mathrm{sec}$ immediately before confinement in the black chamber, confined in the white chamber for $20 \mathrm{sec}$ immediately after confinemen in the black chamber, or not confined in the white cham ber at all. Thus, the animals were exposed to the CSbefore the CS+, the CS+ before the CS-, or just the CSt. "Explicitly unpaired control" subjects receivec identical exposures to the chambers, except that noncontingent footshock was administered $1 \mathrm{~h}$ prior to any such exposure.

\section{Method}

Subjects. The animals were 60 male and female rats, 50-55 day: old. These naive Sprague-Dawley-derived rats were bred and rearec in our colony at the State University of New York at Binghamton Food and water was available ad lib, and the animals were houser in a climate-controlled vivarium. A 16-h-light/8-h-dark cycle wa: employed, with lights going on at $0600 \mathrm{~h}$. The number of subject: assigned to each group was 8-10. All experimental manipulation: were carried out between 1300 and $1800 \mathrm{~h}$.

Apparatus and Procedure. Training and testing was carried ou in two identical, two-compartment aversive conditioning appara tuses with a grid floor. Each compartment, one black and one white. was $26.67 \times 14.29 \times 13.97 \mathrm{~cm}$. The conditioning apparatus alsc had a door between the two compartments which could be loweres in order to confine the animal in either the black or white compart ment. The footshock source was a Lafayette shock generator (A615C) set at .5 mA, 3-sec duration. Control animals receivec footshock in a clear Plexiglas apparatus, similar to the condition. ing apparatus, $1 \mathrm{~h}$ prior to exposure to either compartment.

For the CS+ animals, confinement was limited to the black chamber for $20 \mathrm{sec}$, with footshock delivered during Seconds 8-10 and 18-20. The animals in the CS-/CS+ group received identical treatment, except that, in addition, these animals were confined in the white chamber for $20 \mathrm{sec}$ (where no footshock was delivered) im. mediately prior to confinement in the black chamber (where footshock was delivered). Finally, animals in the $\mathrm{CS}+/ \mathrm{CS}-$ grouf received similar confinement in both chambers, but in reverse order. There was a control group for each of these three experimental groups, treated identically, except that they received noncontingen! footshock prior to exposure to the compartment(s). Control studies conducted in our laboratory had revealed that noncontingent footshock administered just prior to testing does not alter the animals' baseline preference for the black chamber.

There was a $30-\mathrm{sec}$ delay between training and testing. The animals spent this period in a standard wire-mesh holding cage. To begin the test of preference for the black versus white compart. ments, the animal was placed in a position in which it faced the wall and straddled the center line that separated the two compart ments. The door was, of course, lowered (opened). The amount of time the animal spent in each of the compartments was recordec during a 40 -sec preference test. During the test, the animals were free to locomote between compartments. The criterion employed to determine when an animal had crossed into a compartment was entry of both front paws into that compartment.

\section{Results}

A $3 \times 2$ ANOVA $[3$ exposure conditions (CS+, $\mathrm{CS}-/ \mathrm{CS}+, \mathrm{CS}+/ \mathrm{CS}-$ ) $\times 2$ manipulations (experimental or control)] was calculated on the black-compartment percentage preference scores [time spent in black compartment/(time spent in black compartment + time spent in white compartment)]. This analysis revealed that significant conditioning had occurred; that is, the experimental subjects had a lower preference for the black compartment than did the control subjects $[F(1,54)=23.70, p$ $<.001]$. However, this effect must be tempered by the 
main effect of exposure condition $[F(2,54)=5.76, p<$ $.01]$ and the interaction between condition and manipulation $[F(2,54)=23.70, p<.0001]$. These results are illustrated in Figure 1.

In order to interpret these effects and interactions, tests of simple main effects and planned comparisons were performed using the pooled error term, as suggested by Keppel (1973). In retrospect, it was apparent that the level of significance was not affected by use of either the pooled error term or the error term specific to that comparison.

There was a significant difference among the experimental subjects $[\mathrm{F}(2,54)=16.76, \mathrm{p}<.001]$, but not the control subjects $(F<1)$. Planned comparisons performed on just the experimental groups revealed that animals in the CS+/CS- group expressed stronger aversions than did animals in the CS+ group. Additionally, the $\mathrm{CS}-/ \mathrm{CS}+$ animals expressed stronger aversions than did the CS+ animals $[\mathrm{F}(1,54)=33.44, \mathrm{p}<.001]$ or the CS $+/ \mathrm{CS}-$ animals $[\mathrm{F}(1,54)=10.41, \mathrm{p}<.01]$. The Duncan's multiple range test $(\mathrm{p}<.05$ criterion) confirmed these differences and revealed further that although significant conditioning (relative to the unpaired controls) occurred for the CS $+/ \mathrm{CS}-$ and $\mathrm{CS}-/ \mathrm{CS}+$ groups, no such conditioning occurred for the CS+ group.

\section{Discussion}

The results of this experiment with visual CSs are consistent with those obtained by Kucharski and Spear (1984), who employed odor CSs. Both indicate that for one-trial conditioning in these circumstances, exposure to a CSis required. Animals in the odor experiments were, however, tested for their $\mathrm{CS}+$ preference relative to a

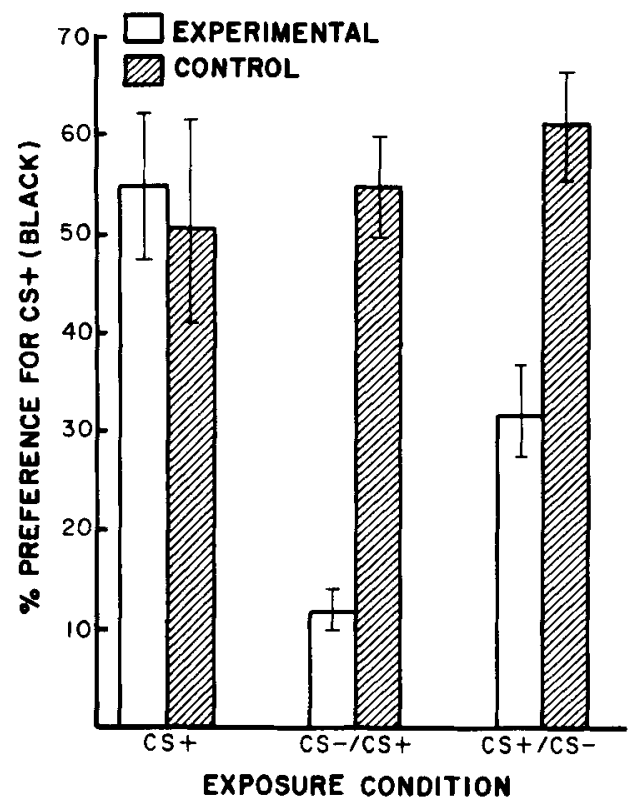

Figure 1. Experiment 1: Mean percent preference for the black compartment (time spent in black compartment divided by time spent in black compartment plus time spent in white compartment) for adult animals as a function of conditioning group $(\mathrm{CS}+, \mathrm{CS}-/ \mathrm{CS}+$, $\mathrm{CS}+/ \mathrm{CS}-$ ) and experimental manipulation (experimental or control). Error bars represent \pm 1 SE. novel odor. In those studies, the animals were not tested for their preference for the CS+ over the CS- because of the possibility that they had learned a preference for the CS- rather than an aversion to the $\mathrm{CS}+$. This possibility was not excluded for visual CSs in Experiment 1 of the present series. This possibility was tested in Experiment 2.

\section{EXPERIMENT 2}

Experiment 2 was undertaken to determine whether the integration of the CS - information with that of the CS+ promotes primarily a conditioned aversion to the black chamber or a conditioned preference for the white chamber. Analogous to the odor experiments by Kucharski and Spear (1984), animals were tested for their preference for the black chamber versus a "novel" gray chamber (CS+ vs. novel). If animals only learn an aversion to black, their preference for gray over black should increase. The animals also were tested for their preference for the white chamber versus the same novel gray chamber (CS- vs. novel). If animals only learn a preference for white, their preference for gray over white should decrease. Alternatively, if animals simply learn to decrease their preference for relatively dark chambers, their preference for the darker of the two chambers employed during testing should decrease. In this case, animals would have both an increased preference for gray in the black versus gray test and a decreased preference for gray in the gray versus white test.

\section{Method}

Subjects. The animals were 49 male and female rats, 50-55 days old. These naive Sprague-Dawley-derived rats were bred and reared in our colony. Housing procedures were as described in Experiment 1

Apparatus and Procedure. The conditioning apparatus was the same as that described for Experiment 1. However, the testing apparatus was modified so that black, white, or gray inserts could be fitted in, depending on the test conditions. The three experimental and three control conditions described for Experiment 1 were included. However, there were two 40 -sec preference tests-black versus gray and gray versus white-counterbalanced for order.

\section{Results}

Preference for the black versus gray chambers. Since there was no effect of order of testing $(F<1)$, these groups were collapsed for further analysis. A $3 \times 2$ ANOVA [ 3 exposure conditions (CS,$+ \mathrm{CS}-/ \mathrm{CS}+$, $\mathrm{CS}+/ \mathrm{CS}-$ ) $\times 2$ manipulations (experimental or control)] was calculated on the black-compartment preference scores [time spent in black compartment/(time spent in black compartment + time spent in gray compartment)] which revealed that significant conditioning had occurred; that is, experimental subjects had lower preferences for the black chamber than did controls $[F(1,43)=63.96$, $\mathrm{p}<.001]$. There was also a main effect of exposure condition $[F(2,43)=7.62, p<.01]$. However, these effects are tempered by an interaction between exposure condition and manipulation $[\mathrm{F}(2,43)=9.14, \mathrm{p}<.01]$. These results are illustrated in Figure 2. 


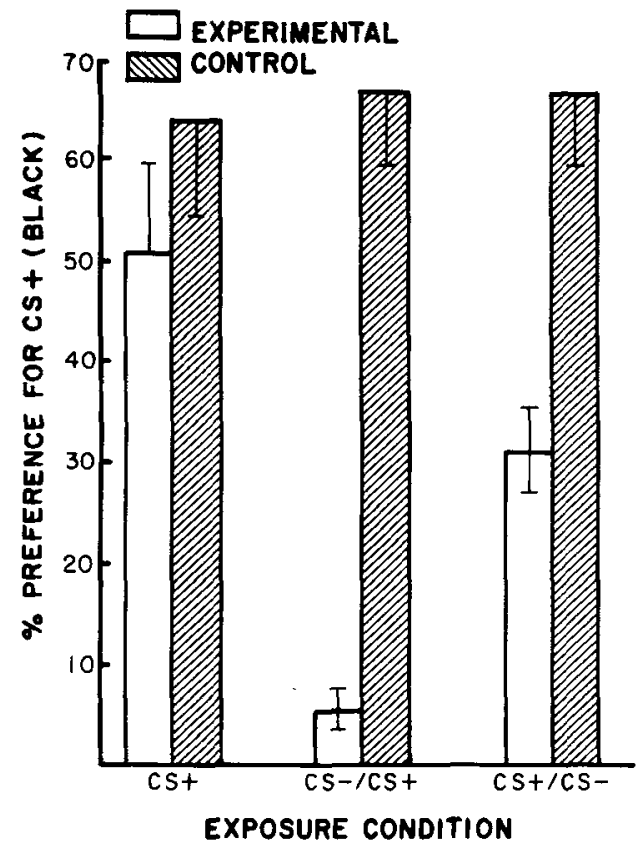

Figure 2. Experiment 2: Mean percent preference for the black compartment (time spent in black compartment divided by time spent in black compartment plus time spent in gray compartment) for adult animals as a function of conditioning group (CS+, $\mathrm{CS}-/ \mathrm{CS}+$, $\mathrm{CS}+/ \mathrm{CS}-$ ) and experimental manipulation (experimental or control).

In order to interpret these effects, tests of simple main effects and planned comparisons were calculated. There were significant differences among the experimental groups $[F(2,43)=16.67, p<.001]$, but not among the control groups $(\mathrm{F}<1)$. Planned comparisons performed on just the experimental groups revealed that animals in the CS+/CS - group expressed stronger aversions than animals in the CS+ group $[\mathrm{F}(1,43)=5.44, \mathrm{p}<.05]$. Additionally, the $\mathrm{CS}-/ \mathrm{CS}+$ group expressed greater aversions than the CS+ group $[\mathrm{F}(1,43)=31.93, \mathrm{p}<$ $.001]$ or the $\mathrm{CS}+/ \mathrm{CS}-$ group $[\mathrm{F}(1,43)=11.00, \mathrm{p}<$ $.01]$. The Duncan's multiple range test ( $\mathrm{p}<.05$ criterion) confirmed these differences and revealed that although the $\mathrm{CS}+/ \mathrm{CS}-$ and $\mathrm{CS}-/ \mathrm{CS}+$ experimental groups had lower preferences for the black compartment than their respective control groups, no such conditioning occurred for the $\mathrm{CS}+$ group. The results of testing black $(\mathrm{CS}+)$ versus gray (novel) essentially duplicated those of testing black $(\mathrm{CS}+)$ versus white $(\mathrm{CS}-$ ) in Experiment 1.

Preferences for the white versus gray chambers. Again, there was no effect of order of test, so these groups were combined for further analysis. A $3 \times 2$ ANOVA [ 3 exposure conditions, $\mathrm{CS}+, \mathrm{CS}-/ \mathrm{CS}+, \mathrm{CS}+/ \mathrm{CS}-$ ) $\times$ 2 manipulations (experimental and control)] was calculated on the gray-compartment preference scores [time spent in gray compartment/(time spent in gray compartment + time spent in white compartment)]. This analysis revealed that experimental subjects had a lower preference for the gray compartment than did control subjects $[F(1,43)=28.88, p<.001]$. But, again, this effect must be tempered by the main effect of exposure conditioning $[F(2,43)=11.89, \mathrm{p}<.01]$ and the interaction between exposure condition and manipulation $[F(2,43)=8.58$ $\mathrm{p}<.01]$. These results are illustrated in Figure 3.

In order to interpret these effects, several simple mai1 effects and planned comparisons were performed. Ther was a significant difference between the experimental sub jects $[F(2,43)=20.37, p<.001]$, but not the contro groups $(F<1)$. Planned comparisons performed on jus the experimental subjects revealed that animals in th $\mathrm{CS}+/ \mathrm{CS}-$ group expressed greater aversions (i.e., lowe preferences for the gray compartment) than did animal in the $\mathrm{CS}+$ group $[\mathrm{F}(1,43)=5.39, \mathrm{p}<.05]$. Addition ally, animals in the CS-/CS+ group expressed greate aversions than did animals in the $\mathrm{CS}+[\mathrm{F}(1,43)=37.83$ $\mathrm{p}<.001]$ or $\mathrm{CS}+/ \mathrm{CS}-$ groups $[\mathrm{F}(1,43)=14.67, \mathrm{p}<$ .01]. The Duncan's multiple range test confirmed thes differences and revealed that although the CS+/CS- anr $\mathrm{CS}-/ \mathrm{CS}+$ experimental groups had lower preferences fo: the gray compartment than their respective control groups no such conditioning occurred for the $\mathrm{CS}+$ group.

\section{Discussion}

The results from Experiment 2 suggest that thest animals learned to decrease their preference for the darke! side of a two-chamber compartment. This was eviden from the increased preference for gray in the black-versus. gray test and the decreased preference for gray in the gray. versus-white test. One argument may be that animals mis. take gray for white in the black-versus-gray preferenct test. However, control animals demonstrated a preference for gray over white, suggesting that they can discriminat the two. Similarly, one could argue that animals are mis. taking gray for black in the gray-versus-white preference

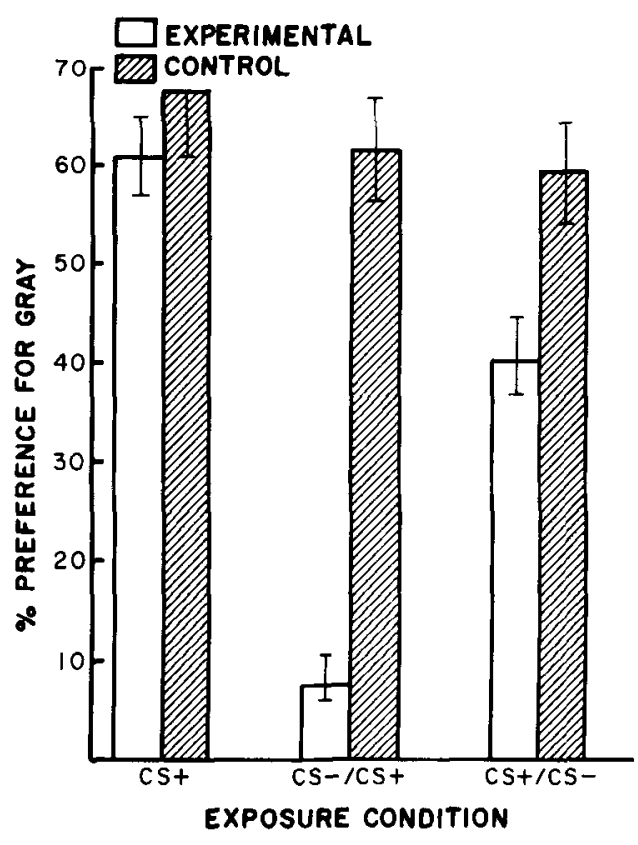

Figure 3. Experiment 2: Mean percent preference for the gray compartment (time spent in gray compartment divided by time spent in gray compartment plus time spent in white compartment). 
test. However, control animals also demonstrated a preference for black over gray, suggesting that they can discriminate the two. These findings are reminiscent of the relational learning that is observed in instrumental discrimination tasks. Mackintosh (1974) argues that the occurrence of transposition or relational learning shows that simultaneous instrumental discrimination learning cannot be reduced to the learning of either approach to $S+$ or avoidance to $S-$ taken in isolation. Our suggestion is that a similar process occurs in the present classical conditioning paradigm, in which no instrumental responses are required by the subject.

Apparently, our procedure allows the animal to learn that it is darker chambers that are predictive of footshock rather than chambers of this size and shape in general. Thus, the animal selects the dark cue as the signal of shock only if given exposure to the white cue that does not predict shock. This implies that there is some representation of the contingency between black and footshock that is, however, not expressed unless the animal experiences a "safe" alternative of a different brightness during training.

The results from both Experiments 1 and 2 also indicate that conditioning is greater when the $\mathrm{CS}$ - exposure precedes the CS+ exposure than vice versa. One interpretation of this finding is that animals exposed to the white chamber after being shocked in the black chamber are more likely to emit escape responses in the white chamber and therefore are less apt to attend to the visual aspects of the compartment than are animals given the opposite order of CSs. This finding conflicts, however, with the expectation that conditioned inhibition to $\mathrm{CS}$ - would be more likely if it immediately followed the footshock given in the CS+. Another explanation is that the retention interval between exposure to the CS+ and test was shorter when the $\mathrm{CS}-$ exposure preceded rather than followed the CS+ exposure. The shorter retention interval may account for the greater conditioning observed. However, this possibility seems unlikely, given that Markiewicz, Kucharski, and Spear (in press) found that, under similar conditions, a retention interval of $24 \mathrm{~h}$ was not disruptive for adult animals.

\section{EXPERIMENT 3}

The results of the previous experiments revealed that animals exposed to a CS- express greater aversions to the $\mathrm{CS}+$ than do animals not exposed to the CS-. Experiment 3 tested some limits of the effect. Does exposure to the CS- change the rat's perception of the CS+ regardless of when it was presented (cf. Kucharski \& Spear, 1984, Experiment 5), or must the rat's memory of the CS- events be active when the CS + events are presented, in order to "integrate" them in terms of dimensions common to each? To assess the importance of a CS- memory on response to $\mathrm{CS}+$, the delay between exposure to the CS - compartment and exposure to the CS + compartment was varied. All animals were later tested for their preference for the black and white chambers.

\section{Method}

Subjects. The animals were 84 male and female Sprague-Dawley rats of the same age, history, and housing conditions as those described for Experiment 1.

Apparatus and Procedure. The training and testing apparatuses and the general procedures for training were the same as those described for Experiment 1. The primary variation was in length of the interval between exposure to CS- and exposure to CS+. Experimental subjects were exposed to the CS- (i.e., the white chamber, where no footshock was administered) for $20 \mathrm{sec}$ immediately, $1 \mathrm{~h}, 6 \mathrm{~h}, 12 \mathrm{~h}$, or $24 \mathrm{~h}$ before being exposed to the $\mathrm{CS}+$ (the black chamber, where footshock was administered). Additionally, one group of animals was exposed only to the CS+ (and not the CS-). The animals were given a 40 -sec test for their preference for the black chamber over the white chamber after a 30 -sec retention interval. Thus, the delay between exposure to the CS+ and test was kept constant for all groups. Control groups were given noncontingent footshock $1 \mathrm{~h}$ prior to exposure to any of the chambers. Again, control studies indicated that noncontingent footshock administered immediately prior to testing does not alter the animals' baseline preference for black over white.

\section{Results and Discussion}

A $6 \times 2$ ANOVA [ 6 exposure-delay groups (No CS-, immediate, 1-h delay, 6-h delay, 12-h delay, or 24-h delay) $\times 2$ experimental manipulations (experimental or control)] revealed that the effects of exposure delay $[F(5,72)=4.06, p<.01]$ and experimental manipulation $[F(1,72)=36.79, p<.0001]$ and the interaction between exposure group and experimental manipulation $[F(5,72)=3.53, p<.01]$ were significant.

To understand the locus of these results, simple main effects and planned comparisons were calculated. There was a significant effect of exposure group for the experimental subjects $[F(5,72)=8.75, p<.001]$ but not for the controls $(\mathrm{F}<1)$. Additionally, the Duncan's multiple range test $(p<.05)$ revealed that the animals exposed to the CS- immediately, $1 \mathrm{~h}, 6 \mathrm{~h}$, or $12 \mathrm{~h}$ before exposure to the $\mathrm{CS}+$ expressed greater aversions than did the animals not exposed to the CS- or those exposed to the $\mathrm{CS}-24 \mathrm{~h}$ prior to exposure to the CS+. Finally, an analysis conducted on the immediate, 1-h delay, 6-h delay, 12-h delay, and 24-h delay experimental groups revealed a significant linear trend $[F(1,72)=23.80, p<$ .001 ]. These results are illustrated in Figures 4 and 5 .

These results indicate that animals benefit from an exposure to a $\mathrm{CS}$ - even when the delay between exposure to CS- and CS+ is as long as $12 \mathrm{~h}$. Nonetheless, there was a significant linear trend indicating that the shorter the delay between $\mathrm{CS}-$ and $\mathrm{CS}+$, the greater the aversion to the CS+.

\section{EXPERIMENT 4A}

The present experiment was designed to test whether the results obtained in Experiments 1 and 3 for adult animals were generalizable to preweanling animals. Of primary importance was the effect of a delay between $\mathrm{CS}-$ and $\mathrm{CS}+$ presentations. Conditioning and its expression, in preweanlings relative to adults, has seemed to be more adversely affected by delays between CS and US or between conditioning and testing (e.g., Baker, 


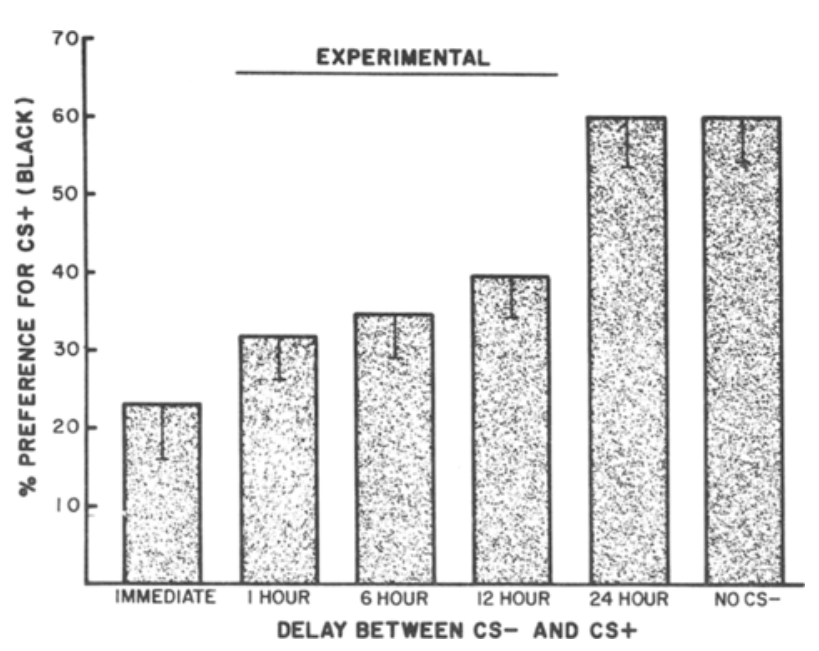

Figure 4. Experiment 3: Mean percent preference for the black compartment (time spent in black compartment divided by time spent in black compartment plus time spent in white compartment) for experimental subjects as a function of interval between CS- and CS + (immediate, 1, 6, 12, or 24 h).

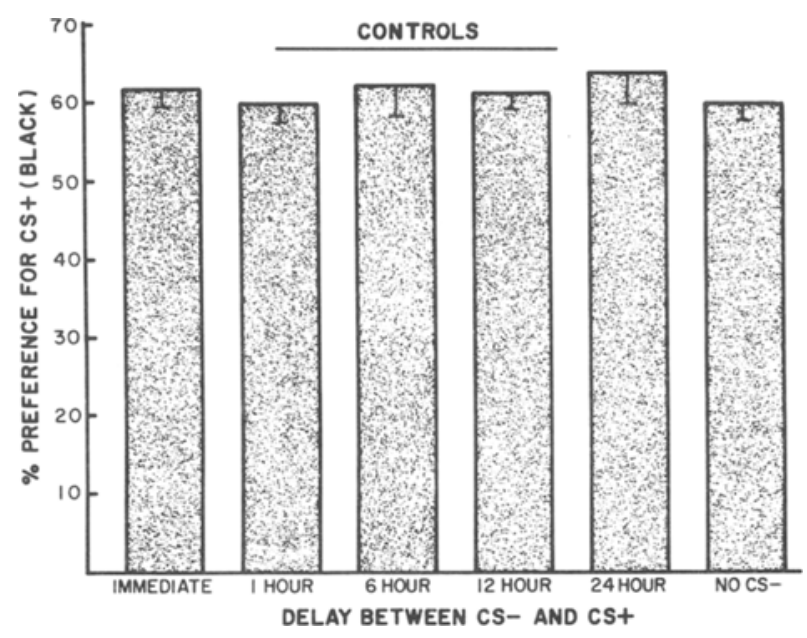

Figure 5. Experiment 3: Mean percent preference for the black compartment (time spent in black compartment divided by time spent in black compartment plus time spent in white compartment) for control subjects as a function of delay between $\mathrm{CS}-$ and $\mathrm{CS}+$.

Baker, \& Kesner, 1977; Klein \& Spear, 1969; Steinert, Infurna, Jardula, \& Spear, 1979; Steinert, Infurna, \& Spear, 1980). If acquired aversion to the CS+ depends on access to the memory of CS-, the evidence of relatively weak retention by preweanlings would predict that delays between $\mathrm{CS}-$ and $\mathrm{CS}+$ would have especially deleterious effects on CS+ conditioning in preweanlings. To test this prediction, preweanling rats were exposed to just the CS+, to the CS+ followed immediately by the $\mathrm{CS}-$, or to the CS- followed immediately, $1 \mathrm{~h}, 6 \mathrm{~h}$, $12 \mathrm{~h}$, or $24 \mathrm{~h}$ later by the CS+.

\section{Method}

Subjects. The animals were 141 16-day-old naive Sprague Dawley-derived rats born and reared in our colony at the Stat University of New York at Binghamton. Births to each mating pai: of male and female adults are checked at $1700 \mathrm{~h}$ in this colony and new pups discovered are termed 0 days of age on that date The pups were housed with both parents and conspecifics in : climate-controlled vivarium with a 16-h-light/8-h-dark cycle witl lights going on at $0600 \mathrm{~h}$.

Apparatus and Procedure. The training and testing apparatu! and general procedures for training and testing were as describer in Experiment 1. For the CS+ animals, confinement was limitec to the black chamber for $20 \mathrm{sec}$, with footshock being administerec during Seconds 8-10 and 18-20. Animals in the CS+/CS- group received identical treatment, except that, in addition, they were confined in the white chamber for $20 \mathrm{sec}$ (where no footshock was administered) immediately after confinement in the black chamber. Additional animals received similar confinement to both compartments, but in reverse order. For the immediate group there was no delay between these exposures. For the 1-h, 6-h, 12-h, and 24-h groups, the delay between confinement to the white and black chambers was 1, 6, 12, and $24 \mathrm{~h}$, respectively. Again, control groups corresponding to each experimental condition were given noncontingent footshock $1 \mathrm{~h}$ prior to exposure to the compartment(s). The animals were given a 40 -sec test of preference for the black chamber over the white chamber after a 30 -sec retention interval. Thus, the delay between exposure to the CS + and test was kept constant for all groups.

\section{Results and Discussion}

There were no differences between the control groups $(F<1)$. Therefore, these groups were collapsed to form one control condition for further comparison. A one-way ANOVA was calculated comparing the eight different conditions (controls, CS,$+ \mathrm{CS}+/ \mathrm{CS}-$, immediate, $1 \mathrm{~h}$, $6 \mathrm{~h}, 12 \mathrm{~h}, 24 \mathrm{~h}$ ) based on the black-compartment preference scores [time spent in black compartment/(time spent in black compartment + time spent in white compartment)]. This analysis revealed a significant effect of treatment condition $[F(7,133)=2.74, p \leq .01]$. These results are illustrated in Figure 6.

To find the locus of this effect and to assess conditioned aversions, several planned comparisons were calculated. As with the adults, the difference between the control condition and the CS+ group did not reach significance $[F(1,133)=1.70, p>.25]$. Also as with the adults, the differences between the control condition and the $\mathrm{CS}+/ \mathrm{CS}-$ group $[\mathrm{F}(1,133)=8.50, \mathrm{p}<.01]$ and between the control condition and the CS-/CS+ group $[F(1,133)=15.58, p<.001]$ were significant. These results indicate that animals given only the $\mathrm{CS}+$ did not acquire (or did not express) a conditioned aversion to that cue, but animals exposed to the CS- either before or after the CS+ did acquire and express such an aversion. These results are similar to those obtained with adult animals in Experiment 1. However, the difference between the CS+/CS- and the CS-/CS + group did not reach significance, as it did for the adult subjects, although the difference was in the same direction; animals in the $\mathrm{CS}-/ \mathrm{CS}+$ group expressed lower preferences than did 


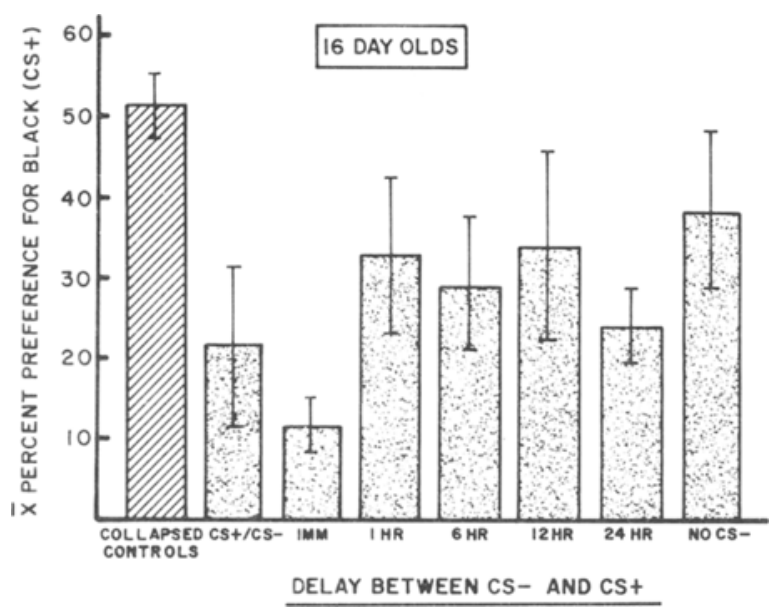

Figure 6. Experiment 4A: Mean percent preference for the black compartment (time spent in black compartment divided by time spent in black compartment plus time spent in white compartment) as a function of conditioning group (controls, $\mathrm{CS}+/ \mathrm{CS}-$, immediate, 1 , 6,12 , or 24 h).

the CS+/CS - group. Additional planned comparisons were calculated between the CS+ group and each of the experimental groups. These comparisons were to determine which groups benefited from the inclusion of the $\mathrm{CS}-$ during conditioning. The comparison between the $\mathrm{CS}+$ group and the CS+/CS- group revealed that the latter group expressed marginally lower preferences than did the former group $[F(1,133)=2.60, p \leq .10]$. The $\mathrm{CS}-/ \mathrm{CS}+$ group did, however, express substantially lower preferences than the CS+ group $[F(1,133)=7.00$, $p<.01]$. However, planned comparisons between the CS+, 1-h, 6-h, 12-h, and 24-h groups did not reach significance $(F<1)$. This result suggests that forgetting about the CS - was complete by $1 \mathrm{~h}$, since the animals in the 1-h group did not demonstrate lower preferences than the group that did not experience the CS-. Adult animals in Experiment 3 did not demonstrate such rapid forgetting.

\section{EXPERIMENT 4B}

The results from the previous experiment suggest that forgetting about the CS- was complete after $1 \mathrm{~h}$ for the preweanling animals. This paradigm provides an opportunity to examine ontogenetic differences in rate of forgetting over relatively short periods; few techniques used to study the ontogeny of learning and memory permit analytic investigation of short-term retention. Experiment 4B varied duration of delay between 0 and $1 \mathrm{~h}$ for preweanlings to determine the course of forgetting during this period.

\section{Method}

Subjects. The animals were 38 16-day-old naive Sprague-Dawley rats. Housing conditions were as described for Experiment $4 \mathrm{~A}$.

Apparatus and Procedure. The training and testing apparatus and general procedures were as described for Experiment 1. The primary variable in the present experiment was, as in Experiments 3 and $4 A$, delay between $C S-$ and $C S+$. In the present experiment, length of the delay varied between 0 and $60 \mathrm{~min}$. Animals had delays of $0 \mathrm{~min}$ (immediate), $5 \mathrm{~min}, 20 \mathrm{~min}, 40 \mathrm{~min}$, and $60 \mathrm{~min}$, respectively. No control conditions were included in this experiment, since the previous experiments had established baseline preference for the black and white chambers.

\section{Results and Discussion}

A one-way ANOVA was calculated comparing the five different treatment conditions (immediate, $5 \mathrm{~min}, 20 \mathrm{~min}$, $40 \mathrm{~min}$, and $60 \mathrm{~min}$ ) based on preference for the black chamber [time spent on black/(time spent on black + time spent on white)]. This analysis did not reveal a significant effect of treatment condition $[\mathrm{F}(4,33)=1.39, \mathrm{p}>.15]$. However, planned comparisons determined that the difference between the 1-h and immediate group was significant $[F(1,33)=4.13, p \leq .05]$. The differences between the 1-h and 5-min groups and between the 1-h and 20min groups also reached this same level of significance $[F(1,33)=4.13, p \leq .05]$. However, the difference between the 1 -h and 40-min groups was only marginally significant $[F(1,33)=2.70, p \leq .10]$. These results are illustrated in Figure 7.

The results from the present experiment suggest that preweanling animals can withstand a delay of between 20 and $40 \mathrm{~min}$. However, significant forgetting occurs if the delay between $\mathrm{CS}-$ and $\mathrm{CS}+$ is extended to $1 \mathrm{~h}$.

\section{GENERAL DISCUSSION}

The results from the present experiment extend those reported by Kucharski and Spear (1984) using odor stimuli. In the present experiments, preweanling (16 days postnatal) and adult animals selected the black cue as the signal of shock only if given exposure to a white cue in the same context that did not predict shock. Animals of

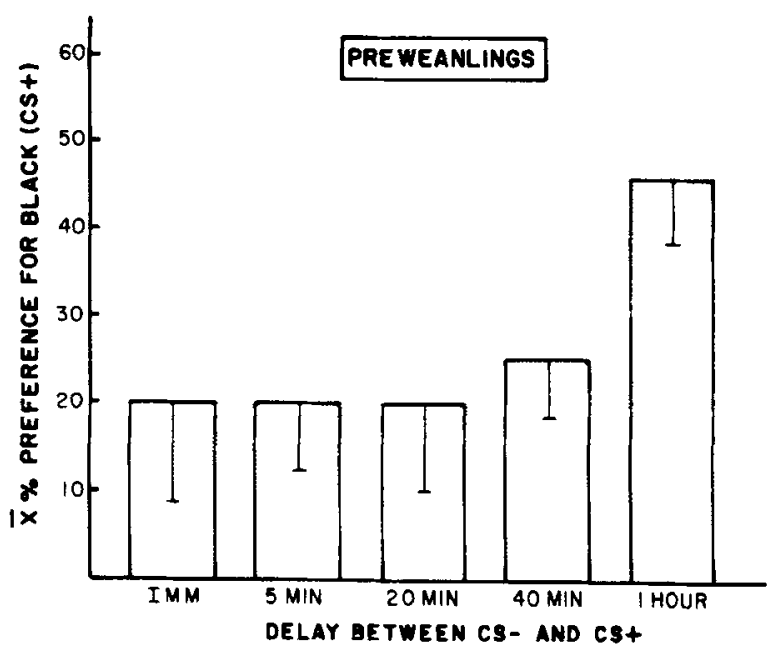

Figure 7. Experiment 4B: Mean percent preference for the black compartment (time spent in black compartment divided by time spent in black compartment plus time spent in white compartment) as a function of interval between $\mathrm{CS}-$ and $\mathrm{CS}+$ (immediate, 5, 20, 40, or $60 \mathrm{~min}$ ) for the preweanlings (16-day-olds). 
both age groups expressed significant one-trial conditioning, but again, only if they were exposed to the CS- . The longer the delay between $\mathrm{CS}-$ and $\mathrm{CS}+$ exposures, the weaker the conditioned aversion to $\mathrm{CS}+$, indicating the importance of an active CS- memory when CS+ was experienced. In the present experiments, therefore, memory for the CS- appears to promote rapid conditioning of a CS+. Exposure to a visual CS- apparently allows the animal to select the visual CS+ cues from among the several cues that the animal can potentially associate with footshock. It should be noted that exposure to the CS - is not equivalent to simple exposure to the conditioning context (cf. Kucharski \& Spear, 1984, Experiment 1). Additionally, exposure to an odor CS- may not promote conditioning to a visual CS+ (Newman, 1984). Thus, it appears that for a CS- to be effective, it must be a cue of the same sensory modality as the CS+.

Results of tests of conditioned aversions in other laboratories can be interpreted within this framework. Sullivan (1979) found that rats could associate a tactile stimulus with footshock over a long CS-US delay. The dependent variable was the amount of time spent touching the object. However, if the rats were not given a substantial experience of safely touching other objects in the experimental box before the introduction of shock, they tended to avoid touching any object in the box. Pelchat, Grill, Rozin, and Jacobs (1983) found that rats could associate taste with footshock, as measured by a decrease in sucrose consumption. However, it was necessary to allow the animals access to a "safe" alternative to sucrose during training. When the animals had no alternative to the shock-paired solution, they were very persistent in sampling sucrose. Together, these results suggest that CSexposures allow the animal to narrow down the possible causes of the US. Consistent with this hypothesis is the finding that exposure to the CS- odor in a context dissimilar to that of the conditioning apparatus did not yield conditioning to the $\mathrm{CS}+$ for either preweanlings or adults (Kucharski \& Spear, 1984). Instead of expressing an aversion to all odors or objects in a certain context, the animal learns an aversion to the CS+ odor.

It is noteworthy that preweanling animals can express significant one-trial conditioning in the present circumstances, given the typical finding that immature animals require several conditioning trials to demonstrate the same level of acquisition as adult animals. Spear (1979b, 1984) has suggested that infant animals differ from adults in their stimulus selection. The stimuli associated or integrated by infant animals may be different from those associated or integrated by adults, even in the same conditioning situation. There are also indications that infant animals are "deficient" in stimulus selection, that is, less selective than adults in what they learn. The younger animals might therefore appear to have special difficulty in forming specific associations between the elements of a conditioning situation (see Spear \& Kucharski, 1984). Exposure to a CS- may attenuate this difficulty and allow the animal to express the same degree and rapidity of conditioning as adult animals.

It is useful to note that younger animals showed more rapid forgetting than adults when there was a delay between the CS- and CS + . Most of the previous paradigms used to study the ontogeny of learning and memory have not permitted such an investigation of short-term memory in such a relatively direct manner, independent of variation in delay of reinforcement which can have motivational as well as associative consequences (e.g., D'Amato, Safarjan, \& Salmon, 1981). In our tests, preweanling rats forgot the CS- events quite rapidly, even with just a 1-h delay between the CS- and CS+. Adult animals did not show this degree of forgetting until there was at least a 12-h delay between the CS- and CS+. This finding indicates that the young rat may begin its exaggerated rate of forgetting soon after a specific event.

This result limits a number of theoretical explanations of infantile amnesia (see Spear, 1979a). Many theories postulate that the factor underlying infantile amnesia is the rapid growth and maturation of sensory and central nervous systems that occurs between the time that the animal is trained in infancy and tested in adulthood. This viewpoint suggests that some aspect of the animal's growth during a retention interval is responsible for the exaggerated forgetting at the end of this interval (Campbell, Misanin, White, \& Lytle, 1974). The extent of neural growth expected over a 1-h period is problematic, but probably it is sufficiently minimal to limit the usefulness of the neural maturation hypothesis in accounting for the forgetting observed. This is not to say, however, that neural growth is irrelevant for infantile amnesia over longer retention intervals.

\section{REFERENCES}

BaKeR, L. K., BAKer, T. B., \& Kesner, R. P. (1977). Taste aversion learning in young and adult rats. Journal of Comparative and Physiological Psychology, 91, 1168-1178.

BRYAN, R. G. (1979). Retention of odor-shock conditioning in neonatal rats: Effect of distribution of practice. Unpublished doctoral dissertation, Rutgers University.

Campeell, B. A., Misanin, J. R., White, B. C., \& Lytle, L. D. (1974). Species differences in ontogeny of memory: Indirect support for neural maturation as a determinant of forgetting. Journal of Comparative and Physiological Psychology, 87, 193-202.

D'Amato, M. R., Safarjan, W. R., \& Salmon, D. (1981). Long-delay conditioning in instrumental learning: Some new findings. In N. E. Spear \& R. R. Miller (Eds.), Information processing in animals: Memory mechanisms. Hillsdale, NJ: Erlbaum.

Garcia, J., \& Koelling, R. A. (1966). Relation of cue to consequence in avoidance learning. Psychonomic Science, 4, 123-124.

Haroutunian, V., Campbell, B. A. (1979). Emergence of introceptive and extraceptive control of behavior in rats. Science, 205, 927-929.

Kelley, M. J. (1982). Stimulus relevance can be learned. Paper presented at meetings of the International Society for Developmental Psychobiology, Minneapolis

KEPPEL, G. (1973). Design and analysis: A researchere's handbook. Englewood Cliffs, NJ: Prentice-Hall.

Klein, S. B., SPEAR, N. E. (1969). Influence of age on short-term retention of active-avoidance learning. Joumal of Comparative and Physiological Psychology, 69, 583-589. 
IUCHARSKI, D., \& SPEAR, N. E. (1984). Conditioning of an aversion to an odor paired with peripheral shock in the developing rat. $D e$ velopmental Psychobiology, 17, 465-479.

MACKINTOSH, N. J. (1974). The psychology of animal learning. London: Academic Press.

MACKINTOSH, N. J. (1975). The theory of attention: Variations in the associability of stimuli with reinforcement. Psychological Review, 82, 276-298.

Markiewicz, B., Kucharski, D., \& Spear, N. E. (in press). Ontogenetic comparison of memory for Pavlovian conditioned aversions to temperature, vibration, odor, or brightness. Developmental Psychobiology.

NEWMAN, S. (1984). Ontogenetic differences in stimulus selection and the processing of multi-element stimuli presented simultaneously across modalities. Unpublished MA thesis, State Univerity of New York, Binghamton.

Pelchat, M. L., Grull, H. J., Rozin, P., \& JACors, J. (1983). Quality of acquired responses to taste by Rattus norvegicus depends on type of associated discomfort. Journal of Comparative Psychology, 97, 140-153.

SPEAR, N. E. (1979a). Experimental analysis of infantile amnesia. In J. F. Kihlstrom \& F. J. Evans (Eds.), Functional disorders of memory. Hillsdale, NJ: Erlbaum.
SPEAR, N. E. (1979b). Memory storage factors in infantile amnesia. In G. Bower (Ed.), Psychology of learning and motivation (Vol. 13). New York: Academic Press.

SPEAR, N. E. (1984). Ecologically determined dispositions control the ontogeny of learning and memory. In R. Kail \& N. E. Spear (Eds.), Comparative perspectives on the development of memory. Hillsdale, NJ: Erlbaum.

SPEAR, N. E., \& KuCHARSKI, D. (1984). Ontogenetic differences in the processing of multi-element stimuli: Potentiation and overshadowing. In H. Roitblat, T. Bever, \& H. Terrace (Eds.), Animal cognition. Hillsdale, NJ: Erlbaum.

Steinert, P. A., Infurna, R. N., Jardula, M. F., \& Spear, N. E. (1979). Effects of CS concentration on long-delay taste aversion learning in preweanling and adult rats. Behavioral and Neural Biology, 27, 487-502.

Steinert, P. A., Infurna, R. N., \& Spear, N. E. (1980). Long-term retention of a conditioned taste aversion in preweanling and adult rats. Animal Learning \& Behavior, 8, 375-381.

Sullivan, L. (1979). Long-delay learning with exteroceptive cue and exteroceptive reinforcement in rats. Australian Journal of Psychology, 31, 21-32.

Sutherland, N. S., \& Mackintosh, N. J. (1971). Mechanisms of animal discrimination learning. London: Academic Press.

(Manuscript received July 20, 1984;

revision accepted for publication January 11, 1985.) 